\title{
P.04 - UNDER THE WEATHER - THE INFLUENCE OF TEMPERATURE AND HUMIDITY IN PSYCHIATRIC EMERGENCY ROOM OBSERVATIONS
}

\author{
Sérgio M. Martinho ${ }^{1}$, Ana Mafalda Carvalheiro ${ }^{1}$, Mário Simões ${ }^{1}$ \\ 1 - Psychiatry and Mental Health Department, Leiria Hospital Centre, Leiria, Portugal
}

\section{Introduction}

The relationship between meteorology and disease is not new. ${ }^{1}$ In fact, meteorological factors have been associated with several medical conditions, such as myocardial infarction ${ }^{2}$ or stroke ${ }^{3}$. The same appears to occur with psychiatric illness. There are known seasonal patterns in psychiatry, such as an increased number of suicides during Spring ${ }^{4}$, an increased number of maniac episodes in Spring and Summer ${ }^{5}$, and worsening of depression in Spring and Winter6. More specifically, it has been noted an inverse relationship between relative humidity and admissions due to affective illness ${ }^{7}$. Moreover, an association between hospitalization due to bipolar disorder and higher numbers for maximum temperature and solar radiation ${ }^{8}$.

\section{Purpose}

We aim to determine the influence of temperature as well as humidity in the number of psychiatric observations in the emergency room (ER) of a general hospital.

\section{Methods}

We collected the daily number of patients who entered the ER referred directly to observation by the psychiatry team, between 1/1/2017 and 31/12/2018, at the Leiria Hospital Centre, Portugal. Similarly, we gathered the values of daily average temperature and humidity, for the same period, from an amateur weather station located around $4 \mathrm{~km}$ from the hospital. The average daily temperature and humidity were obtained by calculating the mean of all measured values of each day. A multiple linear regression was computed to predict the number of patients observed based on daily average temperature and humidity.

\section{Results}

Simple linear regression with average daily temperature as independent variable and with number of patients observed as dependant variable

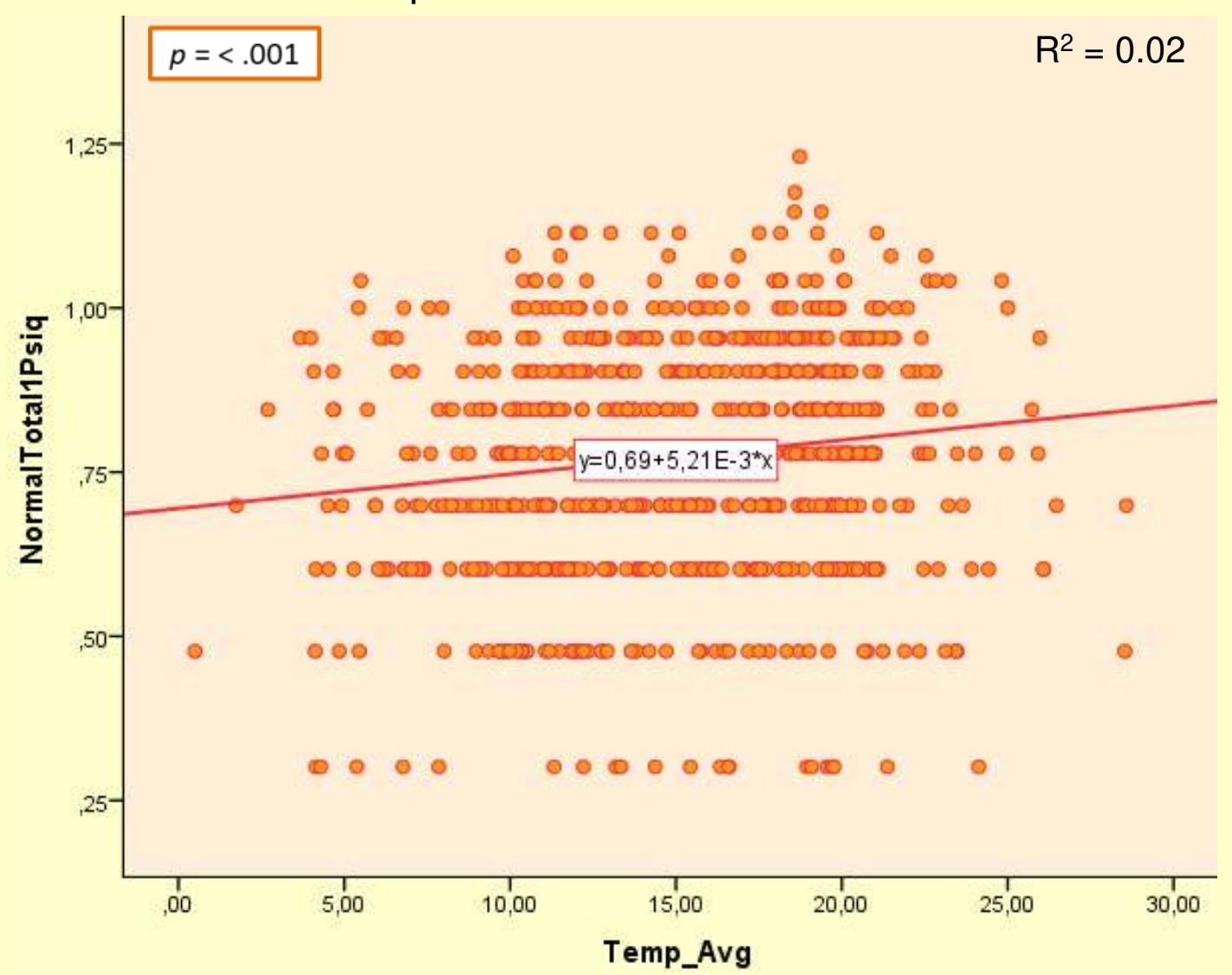

\section{Results}

Simple linear regression with average daily humidity as independent variable and with number of patients observed as dependant variable

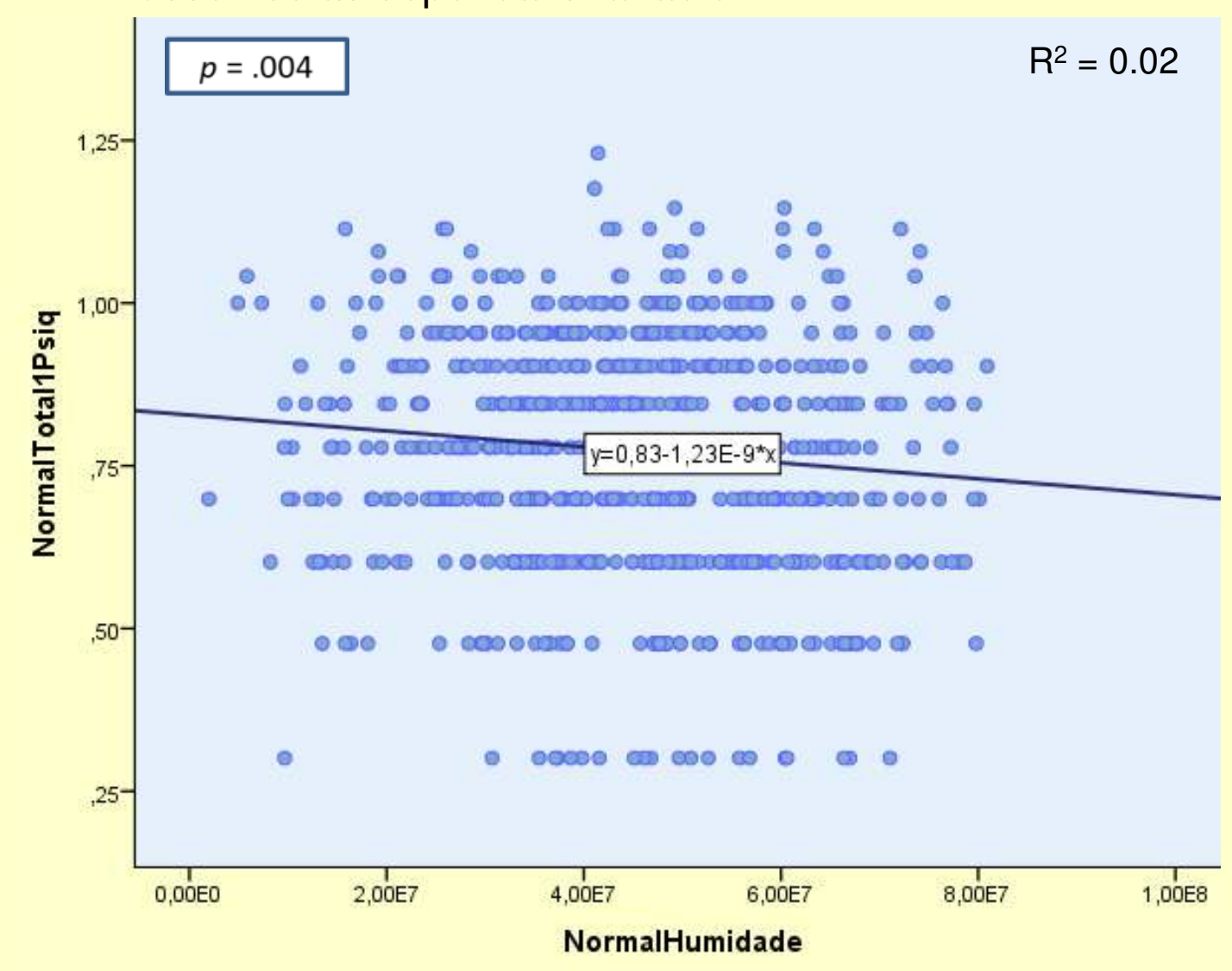

In a multiple linear regression analysis, a significant regression equation was found $(p<.001)$, with an $\mathrm{R}^{2}=0.02$. Daily average temperature was significant predictor of the number of patients referred directly to the psychiatric ER $(B=.04 ; 95 \% \mathrm{Cl}$ $[.01 ; .07] ; p=.004)$, whereas daily average humidity was not $(B=$ $\left.-6.64^{-10} ; 95 \% \mathrm{Cl}\left[-1.58^{-9} ; 2.49^{-10}\right] ; p=.154\right)$.

\section{Conclusions}

Although explaining only $2 \%$ of variance, results suggest that temperature may play a role in resorting to the psychiatric ER. Further studies are necessary to better understand the effect of weather in psychiatric illness.

\section{References:}

1. Bulbena A. Pailhez G, Aceña R, et al. Panic anxiety, under the weather? Int J Biometeorol. 2005:49(4):238-243. doi:10.1007/s00484-004-0236-0 2. Magalhäes R, Silva MC, Correia M, Bailey . Are stroke occurrence and outcome related to weather parameters? Results from a population-based
study in Northern Portugal. Cerebrovasc Dis. 2011

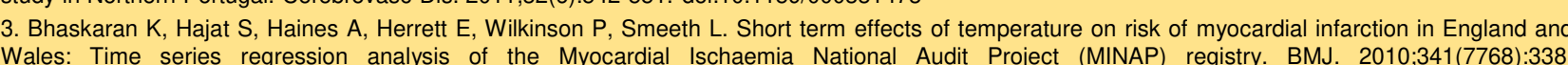
Wales: Time series regression analysis of the Myocardial Ischaemia National Audit Project (MINAP) registry. BMJ. 2010;341(7768):338. 4. Woo JM, Okusaga O, Postolache TT. Seasonality of suicidal behavior. Int J Environ Res Public Health. 2012;9(2):531-547. do:110.3390/jijerph9020531 5. Volpe FM, Del Porto JA. Seasonality of admissions for mania in a psychiatric hospital of Belo Horizonte, Brazil. J Affect Disord. 2006;94(1-3):243-248.
doi:10.1016/.j.j.2.2006.03.025 6.Blacker CVR, Thomas JM, Thompson C. Seasonality prevalence and incidence of depressive disorder in a general practice sample: Identifying

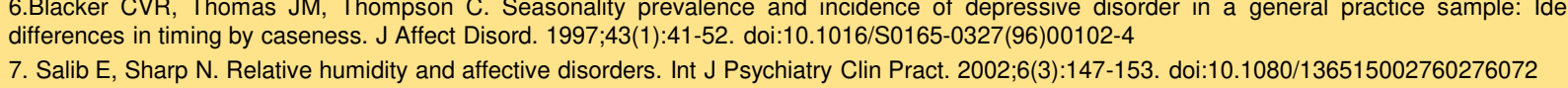
8. Aguglia A, Serafini G, Escelsior A, Canepa G, Amore M, Maina G. Maximum Temperature and Solar Radiation as Predictors of Bipolar Patien 